\title{
Two-Stage Reimplantation in Infected Total Knee Arthroplasty
}

\author{
Yong Seuk Lee, $\mathrm{MD}^{1}$ and Antonia F. Chen, $\mathrm{MD}, \mathrm{MBA}^{2}$ \\ ${ }^{1}$ Department of Orthopaedic Surgery, Seoul National University Bundang Hospital, Seongnam, Korea; ${ }^{2}$ Department of Orthopaedics, Brigham and Women's Hospital, \\ Harvard Medical School, Boston, MA, USA
}

Two-stage reimplantation is considered the gold standard for the management of periprosthetic joint infection. The first stage involves the removal of the prosthesis, followed by extensive debridement of all nonviable tissues, synovectomy, irrigation, and reaming of the medullary canals. Once the joint has been prepared, antibiotic-impregnated cement beads and/or spacer are inserted. Antibiotic-impregnated spacers are now more commonly used, and an increasing number of orthopaedic surgeons are using articulating spacers if indicated. Antibiotics are then prescribed to the patient based on the sensitivities of the infecting organism. The duration of systemic antibiotic use is decreasing, and short courses of antibiotic therapy have been shown to be as efficacious as prolonged therapy between the first and second stages. The second stage of the procedure involves removal of the antibiotic-impregnated cement beads and/or spacer, repeat irrigation and debridement, and final reconstruction with revision components. While two-stage reimplantation was considered the gold standard in many parts of the world, recent studies have demonstrated that it is associated with a considerable failure rate. This may be due to the lack of accurate diagnostic tools for infection eradication, and future investigation of risk factors for failure of the two-stage reimplantation should be conducted.

Keywords: Knee, Arthroplasty, Infection, Spacer, Antibiotics, Reimplantation

\section{Introduction}

One of the most serious complications after total knee arthroplasty (TKA) is periprosthetic joint infection (PJI). Despite tremendous advances in the prevention, diagnosis, and treatment of PJI, it remains the most commonly reported cause of early failure in TKA, resulting in the need for subsequent revision ${ }^{1-3)}$. The Musculoskeletal Infection Society (MSIS) developed diagnostic criteria to standardize and facilitate the diagnostic process (Table $1)^{3)}$. The ultimate goal of the reimplantation procedure is to eradicate infection and reconstruct a functional, and stable joint

Received November 28, 2017; Revised January 4, 2018;

Accepted January 4, 2018

Correspondence to: Antonia F. Chen, MD, MBA

Department of Orthopaedics, Brigham and Women's Hospital, Harvard

Medical School, 75 Francis Street, Boston, MA 02511, USA

Tel: +1-617-525-5935, Fax: +1-617-264-5226

E-mail: afchen@bwh.harvard.edu

This is an Open Access article distributed under the terms of the Creative Commons Attribution Non-Commercial License (http://creativecommons.org/licenses/by-nc/4.0/) which permits unrestricted non-commercial use, distribution, and reproduction in any medium, provided the original work is properly cited. with reduced pain. Treatment of PJI is not possible by antibiotics alone in most cases, and surgical interventions such as irrigation and debridement, one-stage reimplantation, two-stage reimplantation, resection arthroplasty, or amputations are required ${ }^{4)}$.

Most PJI patients require treatment by one- or two-stage reimplantation, but two-stage reimplantation was considered as the gold standard for the management of $\mathrm{PJI}^{5)}$. One-stage revision (irrigation, debridement, and reimplantation performed during the same surgery) is limited to the following criteria: when the type of causative organism is known and is a sensitive gram-positive organism; antibiotic therapy for the causative organism can be administered for 12 weeks; the infection is not polymicrobial; and patient factors are optimal (e.g., adequate soft tissue envelop, adequate bone for reconstruction, and no immunosuppression or significant comorbidities) ${ }^{6-9}$. Therefore, in this review, we will provide an overview focused on two-stage reimplantation in the following order: definition and procedure, antibiotic-impregnated spacers, role and timing of systemic antibiotic administration, optimal timing of reimplantation, and outcomes. 
Table 1. Musculoskeletal Infection Society Diagnostic Criteria for PJI

One of the 3 following criteria must be met for the diagnosis of PJI
1. A sinus tract communicates with the prosthesis
2. A pathogen is identified on culture of $\geq 2$ separate samples of
periprosthetic tissue or fluid
3. Three of the five criteria below are present
1) Serum ESR and serum CRP concentration are elevated.
2) Synovial WBC count is elevated.
3) Synovial neutrophil percentage is elevated.
4) A microorganism is isolated in 1 periprosthetic tissue or fluid
culture
5) $>5$ neutrophil per HPF in $5 \mathrm{HPFs}$ are detected on histological
analysis of periprosthetic tissue at $400 \times$ magnification

PJI: periprosthetic joint infection, ESR: erythrocyte sedimentation rate, CRP: C-reactive protein, WBC: white blood cell, HPF: high power field. ${ }^{\text {a) }}$ Modification by Parvizi et al. ${ }^{3)}$

\section{Definition and Procedure}

Two-stage reimplantation was first described by Insall et al. ${ }^{10)}$. The first stage involves the removal of the prosthesis, followed by extensive debridement of nonviable tissues (including synovectomy), irrigation, and reaming of the medullary canals. Once the joint is prepared, antibiotic-impregnated cement beads and/or spacer are inserted. Postoperatively, antibiotics are administrated based on the sensitivities of the infecting organisms. Reimplantaion is delayed until the antibiotic regimen is completed, the wound has healed, and infection treatment has been confirmed. The second stage of the procedure involves removal of the antibiotic-impregnated cement beads and/or spacer, repeating irrigation and debridement, and final reconstruction with revision components $^{8,10}$.

Many tissue samples from different areas should be collected for microbiological examination, including intramedullary canals and posterior capsule. Extensive debridement is essential for both first and second stages, similar to tumor excision surgery. All septic membranes must be radically excised, and special care needs to be taken to debride the posterior capsule, since it is a potential source of reinfection. Removal of well-fixed components carries the risk of destruction of bone and adjacent soft tissues, and cortical windows may be required for the removal of well-fixed uncemented components. All efforts should be made to minimize bone $l o s s^{5}$. After debridement, copious amount of fluid should be used for irrigation. However, usefulness of pulsatile lavage and the most efficacious antimicrobial solution for irrigation remain inconclusive and unknown ${ }^{5}$.

\section{Antibiotic-Impregnated Spacers (Articulating versus Static)}

Antibiotics can be incorporated into bone cement because commercially available antibiotic-impregnated cement only contains prophylactic doses of antibiotics which are inadequate to manage infection. Appropriate antibiotics should be bactericidal, water soluble, and thermodynamically stable, allow gradual release over an appropriate period of time, and evoke minimal local inflammatory reaction ${ }^{11)}$. Typically, amikacin, ampicillin, cefazolin, ciprofloxacin, gentamicin, penicillin, and vancomycin can be used ${ }^{8)}$. Most importantly, the selection of antibiotics should be based on treating likely pathogens and accompanying culture sensitivities. The amount of antibiotics may be up to $20 \%$ of the total mass of the spacer (e.g., 2-4 g of vancomycin per $40 \mathrm{~g}$ bag of cement), since the mechanical strength of the spacer is not a major concern $^{5}$. However, care should be taken to avoid systemic toxicity such as acute kidney injury ${ }^{12)}$. A maximum of $10 \%$ by weight of antibiotic is generally recommended with a consideration of risk and benefit ${ }^{13)}$.

Antibiotic-impregnated cement spacers can be inserted after irrigation and debridement. The goal of the spacer is to preserve the joint space and reduce soft tissue contracture while delivering high doses of antibiotics ${ }^{5,14}$. Cement beads are also effective for providing a high local concentration of antibiotics; however, the joint is left in a state of pseudoarthrosis which can further complicate the second stage of the procedure ${ }^{8,11,15}$. Spacers can be inserted in a static or dynamic form. Static spacers are inserted to provide joint stability, but they essentially create a temporary joint arthrodesis since no motion is allowed (Fig. 1). Articulating spacers were later introduced to enhance functional status, maintaining range of motion while improving patient satisfaction (Fig. 2) ${ }^{16,17)}$

Static spacers are generally recommended for cases with massive bone loss, lack of functional collateral ligaments, and the need for soft-tissue reconstruction. However, no clear contraindications have been described for the use of either type of spacer ${ }^{5,18}$. While general functional improvement is expected with articulating spacers, the results for infection eradication are similar in individual studies. It is interesting that three systematic reviews were published in a similar time period (2013-2014) ${ }^{17,19,20)}$ which all included a comparable number of articles that were similar. All three articles reported that articulating spacer groups had significantly higher range of motion (articulating vs. static spacer: $100^{\circ}$ vs. $92^{\circ}, 100^{\circ}$ vs. $83^{\circ}, 101^{\circ}$ vs. $91^{\circ}$, respectively ${ }^{17,19,20)}$, although functional scores were similar in the two treatment groups. Re- 

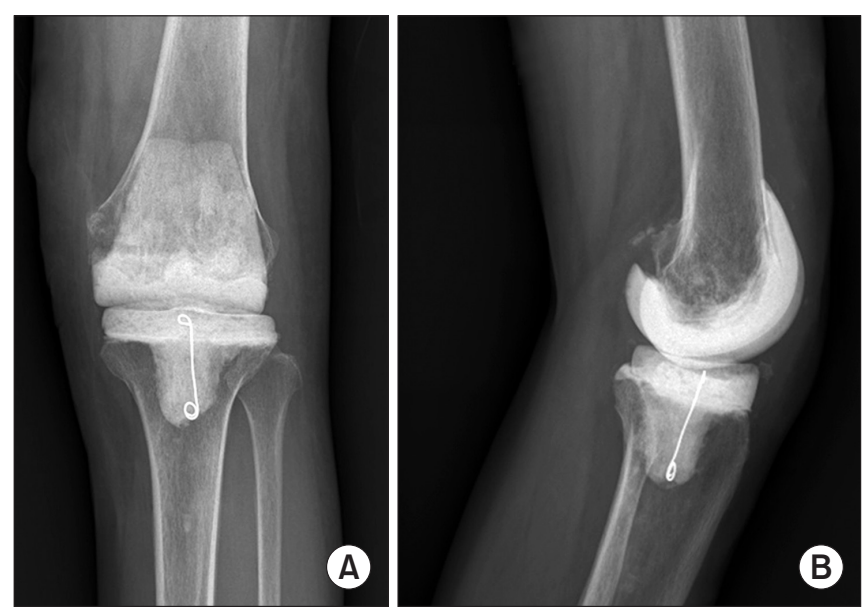

Fig. 1. The articulating spacer is molded according to the size of the resected femoral and tibial surfaces. (A) Anteroposterior view. (B) Lateral view.

garding reinfection rate, different interpretations exist. Pivec et al. ${ }^{19)}$ analyzed outcomes stratified into complex and simple cases, and reported no significant differences in reinfection, complication, or reoperation rates. However, Guild et al. ${ }^{17)}$ reported that articulating spacers showed a lower re-infection rate, facilitated reimplantation, and resulted in less bone loss than static spacers. Voleti et al. ${ }^{20)}$ reported no statistical difference in re-infection rate between the groups, although the mean reinfection was $12 \%$ for static spacers and 7\% for articulating spacers, and six of the seven level III studies demonstrated greater reinfection rates in the static spacer group than in the articulating spacer group. None of the individual studies demonstrated a significant difference in infection eradication secondary to the overall paucity of reinfections.

\section{Role and Timing of Systemic Antibiotics}

When two-stage reimplantation was first introduced, prolonged delivery of intravenous antibiotics (commonly 6 weeks) was recommended $^{10)}$. The 1st and 3rd generation cephalosporins were recommended when Streptococcus was the causative organism. Vancomycin and rifampin combination therapy was recommended for Streptococcus or methicillin-resistant S. epidermidis infections, and aminoglycosides were recommended for gramnegative infections. This is often a significant cost to the patient and healthcare system. Additionally, the usefulness of 6 weeks of antibiotics is questionable since the blood supply to the periarticular tissue may become attenuated, preventing systemically administered antibiotics from reaching the desired site in the setting of infection and surgical trauma ${ }^{8)}$. Meanwhile, intraarticular anti-
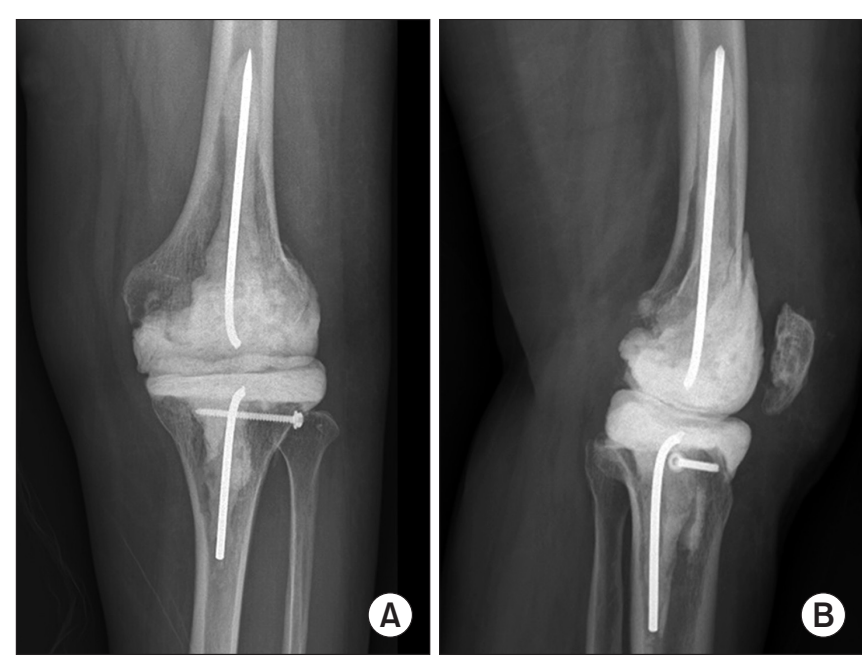

Fig. 2. A static spacer is inserted and it is augmented by intramedullary extension using a Steinmann pin or broken nail. (A) Anteroposterior view. (B) Lateral view.

biotic-impregnated cement spacers can maintain antibiotic levels that are effective against infection for up to 4 months ${ }^{13,21,22}$. Some studies reported comparable results between a short course of intravenous antibiotics (2 weeks of use) and an extended period of use ${ }^{23,24)}$. Hart and Jones ${ }^{23)}$ used articulating cement spacers and short-term parenteral antibiotic therapy in the postoperative period, and infection was successfully eradicated in $88 \%$ of patients. Whittaker et al. ${ }^{24)}$ used systemic vancomycin for two weeks in combination with a vancomycin- and gentamicin-eluting spacer system, and successful infection treatment occurred in $92.7 \%$ of patients. Hsieh et al. ${ }^{21)}$ compared outcome between prolonged (6 weeks) and short-term (1 week) antibiotic use in two-stage reimplantation in infected THA. In this study, infection control and outcomes were similar, but nephrotoxicity and neutropenia occurred in 5 patients who received prolonged antibiotic treatment. Currently, antibiotic treatment is recommended for 4-6 weeks after the first stage; however, the treatment should be individualized, taking into account the infecting organism and the patient. In the first 2 weeks, intravenous administration is recommended, after which oral treatment may be continued depending on the resistance profile of the organism and the availability of an appropriate agent ${ }^{5,25}$. Zywiel et al. ${ }^{26)}$ compared outcomes between patients who received prophylactic oral antibiotics (average 33 days) and 24-72 hours of intravenous antibiotics. This study suggests that the use of oral antibiotic prophylaxis following reimplantation may be appropriate in all patients undergoing twostage revision, even in the absence of any signs of active infection. 


\section{Optimal Timing of Reimplantation}

No single current investigation has accurately or reliably determined the successful eradication of infection after resection arthroplasty in two-stage reimplantation for $\mathrm{PJI}^{5)}$. The international consensus on PJI established a complex algorithm to reach reliable diagnostic accuracy for PJI, and has shown that local proinflammatory cytokines have favorable diagnostic properties for $\mathrm{PJI}^{27}$. However, these designations were not designed for reimplantation and may not adequately detect resolution of infection in a joint previously treated with component explantation and placement of an antibiotic spacer ${ }^{28}$. Compared to primary arthroplasty, assessment of the infection eradication can be more difficult in the setting of reimplantation because patients have often been on prolonged antibiotic therapy and with placement of an antibiotic-impregnated cement spacer. The use of antibiotics can confuse the timing of infection clearance, as antibiotic-impregnated cement spacers can act as a scaffold on which biofilm formation may occur ${ }^{29)}$. Current protocols remain inadequate to address the timing of two-stage reimplantation of PJI.

Clinicians often follow serial serum inflammatory markers, such as erythrocyte sedimentation rate (ESR) and C-reactive protein (CRP), but these tests have been reported to have low sensitivity (range, 0.29 to 0.78 ) (Table 2$)^{6,30-33)}$. The international consensus meeting on PJI demonstrated that local proinflamma- tory cytokines have favorable diagnostic properties for PJI and largely outperform established serum markers such as CRP and $\mathrm{ESR}^{27,34-36)}$. However, these proinflammatory cytokines were not adequately evaluated in reimplantation. Preoperative aspiration prior to reimplantation is associated with a high percentage of false negatives. Synovial white blood cell (WBC) count, percentage of polymorphonuclear cell (\%PMN), gram stain, and culture have also shown low and inconsistent sensitivities (range, 0.05 to 0.82 ) (Table 3$)^{30-33,37,38)}$. Currently, numerous synovial biomarkers are being evaluated as potential candidates ${ }^{39)}$. Regarding tissue culture, Mont et al. .0) $^{40}$ reported a sensitivity of 0.75 and a specificity of 1.00 , while Williams et al. ${ }^{41)}$ reported a sensitivity of 0.83 and a specificity of 0.90 . For synovial fluid \%PMN, Kusuma et al. ${ }^{31)}$ reported a sensitivity of 0.75 and a specificity of 0.66 ; Shukla et al. ${ }^{32)}$ reported a sensitivity of 0.78 and a specificity of 0.82 . Regarding synovial fluid culture, studies ${ }^{30,33,37,41)}$ reported a sensitivity of $0.36-0.80$ and a specificity of $0.63-1$. Other parameters had lower sensitivities and specificities. Regarding synovial fluid WBC count, studies ${ }^{30-32)}$ reported the sensitivity as $0.31-0.78$ and the specificity as $0.39-0.96$. Tissue culture, synovial fluid \%PMN, and synovial fluid culture showed the greatest promise as markers to guide reimplantation, but we cannot provide a firm recommendation regarding the superiority of any one of those tests over others. Therefore, the current approach using multiple tools rather than a single marker is essential. Many authors have

Table 2. Diagnostic Value of the Serum Marker

\begin{tabular}{|c|c|c|c|c|c|c|c|c|}
\hline Study & No. & Serum marker & Sensitivity & Specificity & PPV & NPV & Accuracy & AUC \\
\hline Kusuma et al. ${ }^{31)}$ & 76 & ESR & 0.67 & 0.62 & 0.13 & 0.05 & 0.62 & 0.62 \\
\hline Shukla et al. ${ }^{32)}$ & 86 & ESR & 0.78 & 0.69 & 0.23 & 0.04 & 0.7 & 0.76 \\
\hline \multirow[t]{5}{*}{ Ghanem et al. ${ }^{6)}$} & 109 & $>30$, ESR & $0.65(0.427-0.836)$ & $0.32(0.22-0.44)$ & $0.23(0.14-0.35)$ & $0.75(0.6-0.9)$ & & \\
\hline & & $>45$, ESR & $0.46(0.26-0.67)$ & $0.51(0.39-0.63)$ & $0.23(0.14-0.35)$ & $0.75(0.6-0.9)$ & & \\
\hline & & $\triangle 5, \mathrm{ESR}$ & $0.71(0.49-0.87)$ & $0.24(0.14-0.35)$ & $0.23(0.14-0.35)$ & $0.72(0.51-0.88)$ & & \\
\hline & & $\triangle 10, \mathrm{ESR}$ & $0.67(0.48-0.86)$ & $0.25(0.16-0.37)$ & $0.22(0.13-0.34)$ & $0.7(0.5-0.86)$ & & \\
\hline & & $\triangle 15, \mathrm{ESR}$ & $0.63(0.41-0.81)$ & $0.29(0.19-0.4)$ & $0.22(0.12-0.32)$ & $0.71(0.52-0.86)$ & & \\
\hline Hoell et al. ${ }^{30)}$ & 115 & CRP & 0.42 & 0.84 & 0.35 & 0.88 & & 0.63 \\
\hline Kusuma et al. ${ }^{31)}$ & 76 & CRP & 0.17 & 0.94 & 0.2 & 0.07 & 0.88 & 0.39 \\
\hline Shukla et al. ${ }^{32)}$ & 86 & CRP & 0.67 & 0.55 & 0.15 & 0.07 & 0.56 & 0.55 \\
\hline \multirow[t]{4}{*}{ Ghanem et al. ${ }^{6)}$} & 109 & $>1, \mathrm{CRP}$ & $0.67(0.45-0.84)$ & $0.4(0.28-0.52)$ & $0.28(0.17-0.42)$ & $0.77(0.6-0.9)$ & & \\
\hline & & $>2, \mathrm{CRP}$ & $0.29(0.13-0.51)$ & $0.73(0.6-0.83)$ & $0.27(0.12-0.48)$ & $0.75(0.63-0.85)$ & & \\
\hline & & $\triangle 1.5, \mathrm{CRP}$ & $0.71(0.53-0.89)$ & $0.15(0.07-0.25)$ & $0.22(0.14-0.33)$ & $0.59(0.43-0.82)$ & & \\
\hline & & $\triangle 2, \mathrm{CRP}$ & $0.63(0.43-0.81)$ & $0.23(0.14-0.35)$ & $0.22(0.13-0.34)$ & $0.64(0.43-0.82)$ & & \\
\hline \multirow{2}{*}{$\begin{array}{l}\text { Virolainen } \\
\text { et al. }\end{array}$} & 68 & & 0.67 & 0.79 & & & & \\
\hline & & WBC & 0.44 & 0.95 & & & & \\
\hline
\end{tabular}

PPV: positive predictive value, NPV: negative predictive value, AUC: area under curve, ESR: erythrocyte sedimentation rate, CRP: C-reactive protein, WBC: white blood cell. 
Table 3. Diagnostic Value of the Synovial Marker

\begin{tabular}{|c|c|c|c|c|c|c|c|c|}
\hline Study & No. & Synovial marker & Sensitivity & Specificity & PPV & NPV & Accuracy & AUC \\
\hline \multirow[t]{2}{*}{ Virolainen et al. ${ }^{33)}$} & 68 & Stain & 0.67 & 1 & & & & \\
\hline & 68 & Culture & 0.75 & 1 & & & & \\
\hline Hoell et al. ${ }^{30)}$ & 115 & Culture & $0.05(0.001-0.25)$ & $0.99(0.94-0.999)$ & 0.5 & 0.83 & & \\
\hline Williams et al. ${ }^{41)}$ & 273 & Culture & 0.8 & 0.94 & 0.81 & 0.93 & 0.9 & \\
\hline \multirow[t]{3}{*}{ Nelson et al. ${ }^{37)}$} & 36 & Culture & 0.36 & 0.63 & & & & \\
\hline & 36 & Sonication & 0.82 & 0.5 & & & & \\
\hline & & $\begin{array}{l}\text { Significant and } \\
\text { intermediate }\end{array}$ & 0.63 & 0.78 & & & & \\
\hline Hoell et al. ${ }^{30)}$ & 115 & WBC & 0.31 & 0.39 & 0.11 & 0.71 & & 0.37 \\
\hline \multirow[t]{2}{*}{ Kusuma et al. ${ }^{31)}$} & 76 & WBC & 0.75 & 0.61 & 0.11 & 0.03 & 0.62 & 0.71 \\
\hline & 76 & $\% \mathrm{PMN}$ & 0.75 & 0.66 & 0.12 & 0.02 & 0.66 & 0.71 \\
\hline \multirow[t]{2}{*}{ Shukla et al. ${ }^{32)}$} & 86 & WBC & 0.78 & 0.96 & 0.7 & 0.03 & 0.94 & 0.91 \\
\hline & 86 & $\% \mathrm{PMN}$ & 0.78 & 0.82 & 0.35 & 0.03 & 0.81 & 0.81 \\
\hline
\end{tabular}

PPV: positive predictive value, NPV: negative predictive value, AUC: area under curve, WBC: white blood cell, \%PMN: percentage of polymorphonuclear cell.

Table 4. Diagnostic Value of the Tissue Marker

\begin{tabular}{lrlccccc}
\hline \multicolumn{1}{c}{ Study } & No. & Tissue marker & Sensitivity & Specificity & PPV & NPV & Accuracy \\
\hline Virolainen et al. $^{33)}$ & 68 & Stain & 0.14 & 1 & & & \\
Della Valle et al. $^{42)}$ & 64 & Stain & 0.25 & 0.98 & 0.5 & 0.95 \\
Williams et al. $^{41)}$ & 273 & Culture & 0.83 & 0.9 & 0.74 & 0.94 \\
Mont et al. $^{40)}$ & 34 & Culture & 0.75 & 1 & 1 & 0.98 \\
\hline
\end{tabular}

PPV: positive predictive value, NPV: negative predictive value.

used frozen sections to confirm residual infection during twostage reimplantation. The best current literature regarding twostage reconstruction demonstrated that frozen section analysis only has a sensitivity of $25 \%$, although its specificity is considerably higher ${ }^{42}$. Tissue culture showed a relatively higher sensitivity than other diagnostic methods (range, 0.75 to 0.83 ) (Table 4$)^{38,40)}$. Several studies have examined the utility of technetium/indiumlabelled leukocyte imaging, gallium imaging, FDG-PET scan, and technetium Tc-99 bone marrow imaging in the primary diagnosis of PJI of both the hip and knee ${ }^{33,43,44)}$. Given the significant variability in statistical data and methodological flaws, the American Academy of Orthopedic Surgeons (AAOS) offered a "weak" recommendation for their use in the diagnosis of PJI in select cases of equivocal laboratory investigation ${ }^{45)}$. The MSIS criteria for the diagnosis of PJI did not incorporate nuclear imaging as a reliable method of diagnosis ${ }^{3)}$.

\section{Outcomes}

Current studies report an average high failure rate of $18 \%$ (wide range of $9 \%-33 \%$ ) for utilizing two-stage reimplantation for the treatment of $\mathrm{PJI}^{46)}$. The infection treatment outcomes reported for one- and two-stage reimplantation procedures are comparable, although the indications for one-stage reimplantation are more limited. One systematic review reported that the reinfection rate ranged from $0 \%$ to $41 \%$ for two-stage reimplantation and from $0 \%$ to $11 \%$ for one-stage reimplantation ${ }^{47)}$. However, no prospective randomized clinical trials have been conducted, and most of the studies were only observational ${ }^{47)}$. Recently, another additional systematic review and meta-analysis was conducted. The reinfection rate was $7.6 \%$ (range, $3.4 \%$ to $13.1 \%$ ) in one-stage reimplantation and $8.8 \%$ (range, $7.2 \%$ to $10.6 \%$ ) in two-stage reimplantation. In subgroup analyses, reinfection rates remained generally similar for several study-levels and clinically relevant characteristics. Knee scores and range of motion as postoperative clinical outcomes were similar for both strategies ${ }^{4}$. Only a few 
studies evaluated prognostic factors for successful reimplantation. Mortazavi et al. ${ }^{46)}$ evaluated predictors of failure by comparing two groups (failed and successful two-stage reimplantation). They reported that culture-negative (odds ratio [OR], 4.5 [1.315.7]) and methicillin resistant organisms (OR, 2.8 [0.8-10.3]) increased the risk of failure by more than four- and two-fold, respectively.

\section{Conclusions}

Although two-stage reimplantation is still the gold standard in many parts of the world, different surgical techniques are being considered since there is a considerably high failure rate. This may be due to lack of an accurate diagnostic tool for infection treatment, and there is a need for further investigation of risk factors of failure in two-stage reimplantation. The use of antibioticimpregnated spacers are increasing, and articulating spacers may improve range of motion and increase patient satisfaction. The duration of systemic antibiotic use between stages is getting shorter, and shorter courses of antibiotic therapy have been shown to be as efficacious as prolonged therapy between the first and second stages of treatment for PJI.

\section{Conflict of Interest}

No potential conflict of interest relevant to this article was reported.

\section{References}

1. Parvizi J, Adeli B, Zmistowski B, Restrepo C, Greenwald AS. Management of periprosthetic joint infection: the current knowledge: AAOS exhibit selection. J Bone Joint Surg Am. 2012;94:e104.

2. Parvizi J, Della Valle CJ. AAOS Clinical Practice Guideline: diagnosis and treatment of periprosthetic joint infections of the hip and knee. J Am Acad Orthop Surg. 2010;18:771-2.

3. Parvizi J, Zmistowski B, Berbari EF, Bauer TW, Springer BD, Della Valle CJ, Garvin KL, Mont MA, Wongworawat MD, Zalavras CG. New definition for periprosthetic joint infection: from the Workgroup of the Musculoskeletal Infection Society. Clin Orthop Relat Res. 2011;469:2992-4.

4. Kunutsor SK, Whitehouse MR, Lenguerrand E, Blom AW, Beswick AD; INFORM Team. Re-infection outcomes following one- and two-stage surgical revision of infected knee prosthesis: a systematic review and meta-analysis. PLoS One.

\section{6;11:e0151537.}

5. Gehrke T, Alijanipour P, Parvizi J. The management of an infected total knee arthroplasty. Bone Joint J. 2015;97(10 Suppl A):20-9.

6. Ghanem E, Azzam K, Seeley M, Joshi A, Parvizi J. Staged revision for knee arthroplasty infection: what is the role of serologic tests before reimplantation? Clin Orthop Relat Res. 2009;467:1699-705.

7. Goksan SB, Freeman MA. One-stage reimplantation for infected total knee arthroplasty. J Bone Joint Surg Br. 1992;74: 78-82.

8. Kuzyk PR, Dhotar HS, Sternheim A, Gross AE, Safir O, Backstein D. Two-stage revision arthroplasty for management of chronic periprosthetic hip and knee infection: techniques, controversies, and outcomes. J Am Acad Orthop Surg. 2014;22:153-64.

9. Silva M, Tharani R, Schmalzried TP. Results of direct exchange or debridement of the infected total knee arthroplasty. Clin Orthop Relat Res. 2002;(404):125-31.

10. Insall JN, Thompson FM, Brause BD. Two-stage reimplantation for the salvage of infected total knee arthroplasty. J Bone Joint Surg Am. 1983;65:1087-98.

11. Joseph TN, Chen AL, Di Cesare PE. Use of antibioticimpregnated cement in total joint arthroplasty. J Am Acad Orthop Surg. 2003;11:38-47.

12. Luu A, Syed F, Raman G, Bhalla A, Muldoon E, Hadley S, Smith E, Rao M. Two-stage arthroplasty for prosthetic joint infection: a systematic review of acute kidney injury, systemic toxicity and infection control. J Arthroplasty. 2013;28: 1490-8.

13. Fink B, Vogt S, Reinsch M, Buchner H. Sufficient release of antibiotic by a spacer 6 weeks after implantation in two-stage revision of infected hip prostheses. Clin Orthop Relat Res. 2011;469:3141-7.

14. Qiu XS, Sun X, Chen DY, Xu ZH, Jiang Q. Application of an articulating spacer in two-stage revision for severe infection after total knee arthroplasty. Orthop Surg. 2010;2:299-304.

15. Hsieh $\mathrm{PH}$, Shih $\mathrm{CH}$, Chang YH, Lee MS, Shih HN, Yang WE. Two-stage revision hip arthroplasty for infection: comparison between the interim use of antibiotic-loaded cement beads and a spacer prosthesis. J Bone Joint Surg Am. 2004; 86:1989-97.

16. Hofmann AA, Goldberg TD, Tanner AM, Cook TM. Tenyear experience using an articulating antibiotic cement hip spacer for the treatment of chronically infected total hip. J Arthroplasty. 2005;20:874-9. 
17. Guild GN 3rd, Wu B, Scuderi GR. Articulating vs. static antibiotic impregnated spacers in revision total knee arthroplasty for sepsis: a systematic review. J Arthroplasty. 2014; 29:558-63.

18. Parvizi J, Gehrke T, Chen AF. Proceedings of the international consensus on periprosthetic joint infection. Bone Joint J. 2013;95:1450-2.

19. Pivec R, Naziri Q, Issa K, Banerjee S, Mont MA. Systematic review comparing static and articulating spacers used for revision of infected total knee arthroplasty. J Arthroplasty. 2014;29:553-7.

20. Voleti PB, Baldwin KD, Lee GC. Use of static or articulating spacers for infection following total knee arthroplasty: a systematic literature review. J Bone Joint Surg Am. 2013;95: 1594-9.

21. Hsieh PH, Huang KC, Lee PC, Lee MS. Two-stage revision of infected hip arthroplasty using an antibiotic-loaded spacer: retrospective comparison between short-term and prolonged antibiotic therapy. J Antimicrob Chemother. 2009; 64:392-7.

22. Masri BA, Duncan CP, Beauchamp CP. Long-term elution of antibiotics from bone-cement: an in vivo study using the prosthesis of antibiotic-loaded acrylic cement (PROSTALAC) system. J Arthroplasty. 1998;13:331-8.

23. Hart WJ, Jones RS. Two-stage revision of infected total knee replacements using articulating cement spacers and shortterm antibiotic therapy. J Bone Joint Surg Br. 2006;88:10115.

24. Whittaker JP, Warren RE, Jones RS, Gregson PA. Is prolonged systemic antibiotic treatment essential in two-stage revision hip replacement for chronic Gram-positive infection? J Bone Joint Surg Br. 2009;91:44-51.

25. Lichstein P, Gehrke T, Lombardi A, Romano C, Stockley I, Babis G, Bialecki J, Bucsi L, Cai X, Cao L, de Beaubien B, Erhardt J, Goodman S, Jiranek W, Keogh P, Lewallen D, Manner P, Marczynski W, Mason JB, Mulhall K, Paprosky W, Patel P, Piccaluga F, Polkowski G, Pulido L, Stockley I, Suarez J, Thorey F, Tikhilov R, Velazquez JD, Winkler H. One-stage versus two-stage exchange. J Orthop Res. 2014;32 Suppl 1: S141-6.

26. Zywiel MG, Johnson AJ, Stroh DA, Martin J, Marker DR, Mont MA. Prophylactic oral antibiotics reduce reinfection rates following two-stage revision total knee arthroplasty. Int Orthop. 2011;35:37-42.

27. Zmistowski B, Della Valle C, Bauer TW, Malizos KN, Alavi A, Bedair H, Booth RE, Choong P, Deirmengian C, Ehrlich
GD, Gambir A, Huang R, Kissin Y, Kobayashi H, Kobayashi N, Krenn V, Drago L, Marston SB, Meermans G, Perez J, Ploegmakers JJ, Rosenberg A, Simpendorfer C, Thomas P, Tohtz S, Villafuerte JA, Wahl P, Wagenaar FC, Witzo E. Diagnosis of periprosthetic joint infection. J Arthroplasty. 2014;29(2 Suppl):77-83.

28. Frangiamore SJ, Siqueira MB, Saleh A, Daly T, Higuera CA, Barsoum WK. Synovial cytokines and the MSIS criteria are not useful for determining infection resolution after periprosthetic joint infection explantation. Clin Orthop Relat Res. 2016;474:1630-9.

29. Vielgut I, Sadoghi P, Wolf M, Holzer L, Leithner A, Schwantzer G, Poolman R, Frankl B, Glehr M. Two-stage revision of prosthetic hip joint infections using antibioticloaded cement spacers: when is the best time to perform the second stage? Int Orthop. 2015;39:1731-6.

30. Hoell S, Moeller A, Gosheger G, Hardes J, Dieckmann R, Schulz D. Two-stage revision arthroplasty for periprosthetic joint infections: what is the value of cultures and white cell count in synovial fluid and CRP in serum before second stage reimplantation? Arch Orthop Trauma Surg. 2016;136: 447-52.

31. Kusuma SK, Ward J, Jacofsky M, Sporer SM, Della Valle CJ. What is the role of serological testing between stages of twostage reconstruction of the infected prosthetic knee? Clin Orthop Relat Res. 2011;469:1002-8.

32. Shukla SK, Ward JP, Jacofsky MC, Sporer SM, Paprosky WG, Della Valle CJ. Perioperative testing for persistent sepsis following resection arthroplasty of the hip for periprosthetic infection. J Arthroplasty. 2010;25(6 Suppl):87-91.

33. Virolainen P, Lahteenmaki H, Hiltunen A, Sipola E, Meurman O, Nelimarkka O. The reliability of diagnosis of infection during revision arthroplasties. Scand J Surg. 2002;91: 178-81.

34. Deirmengian C, Hallab N, Tarabishy A, Della Valle C, Jacobs JJ, Lonner J, Booth RE Jr. Synovial fluid biomarkers for periprosthetic infection. Clin Orthop Relat Res. 2010;468:201723.

35. Deirmengian C, Kardos K, Kilmartin P, Cameron A, Schiller K, Parvizi J. Diagnosing periprosthetic joint infection: has the era of the biomarker arrived? Clin Orthop Relat Res. 2014;472:3254-62.

36. Diaz-Ledezma C, Higuera CA, Parvizi J. Success after treatment of periprosthetic joint infection: a Delphi-based international multidisciplinary consensus. Clin Orthop Relat Res. 2013;471:2374-82. 
37. Nelson CL, Jones RB, Wingert NC, Foltzer M, Bowen TR. Sonication of antibiotic spacers predicts failure during twostage revision for prosthetic knee and hip infections. Clin Orthop Relat Res. 2014;472:2208-14.

38. Atkins D, Best D, Briss PA, Eccles M, Falck-Ytter Y, Flottorp S, Guyatt GH, Harbour RT, Haugh MC, Henry D, Hill S, Jaeschke R, Leng G, Liberati A, Magrini N, Mason J, Middleton P, Mrukowicz J, O'Connell D, Oxman AD, Phillips B, Schunemann HJ, Edejer T, Varonen H, Vist GE, Williams JW Jr, Zaza S; GRADE Working Group. Grading quality of evidence and strength of recommendations. BMJ. 2004;328: 1490.

39. Wyatt MC, Beswick AD, Kunutsor SK, Wilson MJ, Whitehouse MR, Blom AW. The alpha-defensin immunoassay and leukocyte esterase colorimetric strip test for the diagnosis of periprosthetic infection: a systematic review and metaanalysis. J Bone Joint Surg Am. 2016;98:992-1000.

40. Mont MA, Waldman BJ, Hungerford DS. Evaluation of preoperative cultures before second-stage reimplantation of a total knee prosthesis complicated by infection: a comparison-group study. J Bone Joint Surg Am. 2000;82:1552-7.

41. Williams JL, Norman P, Stockley I. The value of hip aspiration versus tissue biopsy in diagnosing infection before exchange hip arthroplasty surgery. J Arthroplasty. 2004;19:5826.

42. Della Valle CJ, Bogner E, Desai P, Lonner JH, Adler E, Zuckerman JD, Di Cesare PE. Analysis of frozen sections of intraoperative specimens obtained at the time of reoperation after hip or knee resection arthroplasty for the treatment of infection. J Bone Joint Surg Am. 1999;81:684-9.

43. Huang MJ, Hsieh PH, Ueng SW, Ho KC, Yen TC, Lee MS. Use of positron emission tomography to detect infection around antibiotic-loaded cement spacers in patients with high C-reactive protein levels. Orthopedics. 2011;34:e605-9.

44. Scher DM, Pak K, Lonner JH, Finkel JE, Zuckerman JD, Di Cesare PE. The predictive value of indium-111 leukocyte scans in the diagnosis of infected total hip, knee, or resection arthroplasties. J Arthroplasty. 2000;15:295-300.

45. Della Valle C, Parvizi J, Bauer TW, DiCesare PE, Evans RP, Segreti J, Spangehl M, Watters WC 3rd, Keith M, Turkelson CM, Wies JL, Sluka P, Hitchcock K; American Academy of Orthopaedic Surgeons. American Academy of Orthopaedic Surgeons clinical practice guideline on: the diagnosis of periprosthetic joint infections of the hip and knee. J Bone Joint Surg Am. 2011;93:1355-7.

46. Mortazavi SM, Vegari D, Ho A, Zmistowski B, Parvizi J. Two-stage exchange arthroplasty for infected total knee arthroplasty: predictors of failure. Clin Orthop Relat Res. 2011; 469:3049-54.

47. Masters JP, Smith NA, Foguet P, Reed M, Parsons H, Sprowson AP. A systematic review of the evidence for single stage and two stage revision of infected knee replacement. BMC Musculoskelet Disord. 2013;14:222. 